\title{
Incorporation of hydrogen and others atomic impurities in natural olivines
}

\author{
Sylvie DeMOUCHY' AND OLIVIER ALARD ${ }^{12}$
}

Géosciences Montpellier, Université de Montpellier \& CNRS, 34095 Montpellier, France.

${ }_{2}^{2}$ Department of Earth and Planetary Science, Macquarie University, Sydney NSW 2109, Australia

Taking advantages of recent analytical advances, we investigate the potential coupled $\mathrm{H}$ and chemical impurities in 17 olivine crystals from ten different localities. Olivine specimens were prepared as cut and polished prisms, and their major (micro X-ray fluorescence) and minor, trace, and ultra-trace element concentrations (laser ablation inductively coupled plasma mass spectrometry) were determined. Hydrogen concentrations were quantified using both unpolarized and polarized Fourier transform infrared spectroscopy (FTIR).

Forsterite contents range from 83.2 to $94.1 \%$, in agreement with the geological diversity of the specimens. Hydrogen concentrations range from 0 (dry) to 54 ppm $\mathrm{H}_{2} \mathrm{O}$ by weight and are homogenous per crystal (except for one olivine from Patagonia). Total minor element concentrations range from 3487 to $6493 \mathrm{ppm}$, and are dominated by $\mathrm{Ni}$, $\mathrm{Mn}$, and $\mathrm{Ca}$ or $\mathrm{B}$. Total rare Earth element and extended trace element concentrations are very low $(<1 \mathrm{ppm})$. Magmatic olivine (La Réunion, France) and hydrothermal olivine from a metamorphic setting (Norway) show the most and least atomic impurities, respectively, and mantlederived olivines have concentrations between these two extremes.

Hydrogen concentrations are inversely correlated with di-, tri-, and tetravalent impurities, indicating their competition for metal vacancies. However, we observe a broad positive correlation between $\mathrm{OH}$ bands at 3575 and $3525 \mathrm{~cm}^{-1}$ and Ti concentration, confirming the existence of a titanium clinohumite-like point defect. Nonetheless, Ti impurities do not exclusively control 'bulk' hydrogen incorporation in olivine due to the co-existence with other atomic impurities. Our results demonstrate that hydrogen behaves as an incompatible and opportunist element in olivine lattice. 